\title{
Potestad sancionadora y comunidades autónomas
}

\author{
Juan Manuel Alegre Ávila
}

Sumario: I. COMPETENCIA SUSTANTIVA Y COMPETENCIA SANCIONADORA: EL CARÁCTER INSTRUMENTAL DE LA POTESTAD SANCIONADORA. II. LOS CRITERIOS QUE ARTICULAN LA COMPETENCIA SANCIONADORA DEL ESTADO $Y$ DE LAS COMUNIDADES AUTÓNOMAS. III. LA COMPETENCIA SANCIONADORA EN MATERIA AMBIENTAL: LA FUNCIÓN DE "UNIFORMIDAD RELATIVA" DE LAS NORMAS SANCIONADORAS ESTATALES. IV. POTESTAD SANCIONADORA Y SEGURIDAD SOCIAL.

\section{COMPETENCIA SUSTANTIVA Y COMPETENCIA SANCIONADORA: EL CARÁCTER INSTRUMENTAL DE LA POTESTAD SANCIONADORA}

1. En el fundamento jurídico 13 de la STC 37/2002² puede leerse:

"[...] ha de recordarse que la potestad sancionadora no constituye un título competencial autónomo (STC 156/1995, de 26 de octubre, fundamento jurídico 7) y que las Comunidades Autónomas tienen potestad sancionadora en las materias sustantivas sobre las que ostenten competencias, pudiendo establecer o modular tipos y sanciones en el marco de las normas o principios básicos del Estado, pues tal posibilidad es inseparable de las exigencias de prudencia o de oportunidad que pueden variar en los distintos ámbitos territoriales, debiendo además acomodarse sus disposiciones a las garantías dispuestas en este ámbito del derecho administrativo sancionador (STC 227/1988, de 9 de julio, fundamento jurídico 29)".

Doctrina cuya aplicación al caso de la potestad sancionadora en materia de función pública se traduce en la siguiente afirmación:

1 Catedrático de Derecho Administrativo. Universidad de Cantabria. Ex Letrado del Tribunal Constitucional.

2 STC 37/2002, de 14 de febrero; ponente: Vives Antón. Cuestiones de inconstitucionalidad acumuladas números 71/1994 y 243/1995, promovidas por la Sección Primera de la Sala de lo Contencioso-Administrativo del Tribunal Superior de Justicia de Cataluña en relación con los artículos 92.2 de la Ley 7/1985, de 2 de abril, Reguladora de las Bases del Régimen Local, y 74.4, 93 n), 97.1 d) y 99 de la Ley de Cataluña 17/1985, de 23 de julio, de la Función Pública de la Administración de la Generalidad. 
“[...] el carácter básico del artículo 31.1 de la Ley 30/1984, de 2 de agosto, no excluye o impide la tipificación como faltas muy graves de otras conductas por las Comunidades Autónomas mediante su actividad legiferante en desarrollo de la normativa básica estatal siempre que sean compatibles, no contradigan, reduzcan o cercenen dicha normativa básica".

2. "La potestad sancionadora no constituye un título competencial autónomo", señala el fundamento jurídico 7 de la STC 156/1995³, al que se remite el antes transcrito. $\mathrm{Y}$, a continuación, reproduce el texto que sigue del fundamento jurídico 8 de la STC 87/1987:

"Las Comunidades Autónomas pueden adoptar normas administrativas sancionadoras cuando, teniendo competencia sobre la materia sustantiva de que se trate, tales disposiciones se acomoden a las garantías dispuestas en este ámbito del derecho sancionador (artículo 25.1, básicamente), y no introduzcan divergencias irrazonables y desproporcionadas al fin perseguido respecto del régimen jurídico aplicable en otras partes del territorio"4.

Afirmación cuyo desarrollo se pormenoriza, de la mano de las SSTC 149/1991 y 102/1995, en el fundamento jurídico 8, que extrae las oportunas consecuencias a propósito de la potestad sancionadora en materia ambiental:

“Como se indica en la STC 149/1991, las normas que tipifican infracciones y establecen sanciones no son sino parte de las normas que enuncian los deberes y obligaciones cuyo incumplimiento se tipifica como falta, por lo que aparecen como complemento necesario de las normas sobre protección del medio ambiente. Ello permite -y así lo hemos declarado en la STC 102/1995, fundamento jurídico 32- que, con la finalidad de garantizar unos mínimos de protección comunes a todo el territorio nacional, el Estado pueda establecer con carácter básico un catálogo mínimo de conductas -ampliable por el legislador autonómico- que en todo caso se deberán considerar infracciones administrativas (artículo 38 LCEN); asimismo, que pueda determinar que algunas de esas conductas tendrán siempre la calificación de infracciones graves (artículo 39.2), y, por último, que pueda esta-

3 STC 156/1995, de 26 de octubre; ponente: González Campos. Recurso de inconstitucionalidad interpuesto por el Presidente del Gobierno contra diversos preceptos de la Ley del Parlamento Vasco 5/1989, de 6 de julio, de Protección y Ordenación de la Reserva de la Biosfera de Urdaibai.

4 Doctrina que con parecidas palabras se reitera en el fundamento jurídico 29 de la STC 227/1988, de 29 de noviembre [ponente: Leguina Villa. Recursos de inconstitucionalidad y conflictos positivos de competencia acumulados deducidos en relación con la Ley 29/1985, de 2 de agosto, de Aguas, y normas reglamentarias de desarrollo]:

“[...] procede recordar ahora la doctrina de este Tribunal establecida en la STC 87/1985, de 16 de julio, y reiterada en las SSTC 102/1985, de 4 de octubre; 137/1986, de 6 de noviembre, y 48/1988, de 22 de marzo, entre otras, según la cual las Comunidades Autónomas tienen potestad sancionadora en las materias sustantivas sobre las que ostentan competencias y, en su caso, pueden regular las infracciones y sanciones ateniéndose a los principios básicos del ordenamiento estatal, pero sin introducir divergencias irrazonables o desproporcionadas al fin perseguido respecto del régimen jurídico aplicable en otras partes 
blecer los criterios generales para la determinación de la gravedad de las infracciones, así como una escala de sanciones con unos límites máximos y mínimos (artículo 39.1). Ahora bien, respecto de este concreto extremo también hemos indicado que tanto las sanciones como la escala cuantitativa para las multas no son sino clasificaciones genéricas "necesitadas por sí mismas de un desarrollo legislativo a cargo de las Comunidades Autónomas". Esto es, constituyen "una regla mínima, cuya modulación a través de las circunstancias modificativas de la responsabilidad queda en manos de los legisladores y administradores autonómicos para configurarlas en normas y aplicarlas al caso concreto, respectivamente" (STC 102/1995, fundamento jurídico 32).

3. $\mathrm{Y}$, por ofrecer una tercera muestra, referida ésta al comercio interior, en el fundamento jurídico 8 de la STC $124 / 2003^{5}$ se dice:

“En relación a la potestad sancionadora debe señalarse ante todo su carácter instrumental respecto del ejercicio de las competencias sustantivas, como hemos señalado en diversas resoluciones (SSTC 48/1988, de 22 de marzo, fundamento jurídico 25; 227/1988, de 29 de noviembre, fundamento jurídico 29; 96/1996, de 30 de mayo, fundamento jurídico 7). De ahí que las Comunidades Autónomas puedan adoptar normas administrativas sancionadoras cuando tengan competencia sobre la materia sustantiva de que se trate, debiendo acomodarse las disposiciones que dicten a las garantías constitucionales dispuestas en este ámbito del Derecho administrativo sancionador (artículo 25.1 C.E.), y no introducir divergencias irrazonables y desproporcionadas al fin perseguido respecto del régimen jurídico aplicable en otras partes del territorio (artículo 149.1.1 C.E. SSTC 87/1985, de 16 de julio, fundamento jurídico 8; 196/1996, de 28 de noviembre, fundamento jurídico 3). La regulación de las infracciones y sanciones que las Comunidades Autónomas lleven a cabo estará pues limitada por los principios básicos del ordenamiento estatal (STC 227/1988, fundamento jurídico 29), y, en todo caso, habrá de atenerse a lo dispuesto en el artículo 149.1.1 C.E.; de igual modo, el procedimiento sancionador habrá de ajustarse al administrativo común, cuya configuración es de exclusiva competencia estatal (artículo 149.1.18 C.E.), sin que ello implique que toda regulación del Derecho administrativo sancionador, por el hecho de afectar al ámbito de los derechos fundamentales, sea competencia exclusiva del Estado" (STC 87/1985, de 16 de julio, fundamento jurídico 8$)^{6}$.

5 STC 124/2003, de 19 de junio; ponente: Pérez Vera. Recursos de inconstitucionalidad interpuestos por el Gobierno de la Comunidad Foral de Navarra contra diversos preceptos de la Ley 7/1996, de 15 de enero, de ordenación del comercio minorista, y de la Ley Orgánica 2/1996, de 17 de enero, complementaria de la de ordenación del comercio minorista.

6 En relación, asimismo, con este ámbito del comercio interior, las SSTC 157/2004, de 21 de septiembre (ponente: Jiménez Sánchez. Recurso de inconstitucionalidad interpuesto por el Presidente del Gobierno de la Nación contra diversos preceptos de la Ley Foral 17/2001, de 12 de julio, reguladora del comercio en Navarra), en particular, fundamentos jurídicos 15 y 16, y 254/2004, de 22 de diciembre (ponente: Sala Sánchez. Cuestión de inconstitucionalidad promovida por la Sección Novena de la Sala de lo Contencioso-Administrativo del Tribunal Superior de Justicia de Madrid en relación con la Ley de la Comunidad de Madrid 4/1994, de 6 de junio, de calendario y horarios comerciales), fundamento jurídico 7. 


\section{LOS CRITERIOS QUE ARTICULAN LA COMPETENCIA SANCIONADORA DEL ESTADO Y DE LAS COMUNIDADES AUTÓNOMAS}

1. Función pública, medio ambiente y comercio interior, pues, como tres ámbitos en los que se despliega, al socaire de su competencia sustantiva o material, la potestad, normativa y no sólo de ejecución, sancionadora de las Comunidades Autónomas. Una competencia que se articula en concurrencia con la estatal, según el binomio bases-desarrollo (artículo 149.1.18 y $23^{\mathrm{a}}$ de la Constitución, por lo que hace, respectivamente, a los dos primeros supuestos; en el caso del comercio interior, diversos títulos estatales, entre otros, el previsto en el artículo 149.1.13 ${ }^{\mathrm{a}}$ del texto constitucional, delimitan el ámbito de la competencia autonómica), de suerte que su ejercicio viene enmarcado por estos principios o criterios:

- El carácter dependiente, no autónomo, de la potestad (normativa) sancionadora. En otros términos, su "carácter instrumental respecto del ejercicio de las competencias sustantivas".

— La posibilidad de "establecer o modular tipos y sanciones en el marco de las normas o principios básicos del Estado”.

- Posibilidad que es "inseparable de las exigencias de prudencia o de oportunidad que pueden variar en los distintos ámbitos territoriales".

- El respeto por las normas sancionadoras autonómicas a la "normativa básica estatal", de modo que la validez de aquéllas está supeditada a su compatibilidad, no contradicción, reducción o cercenamiento en relación a dicha normativa básica estatal.

- En particular, proscripción de la introducción de “divergencias irrazonables y desproporcionadas al fin perseguido respecto del régimen jurídico aplicable en otras partes del territorio" (artículo 149.1.1ª de la Constitución).

- El acomodamiento de las disposiciones sancionadoras autonómicas a "las garantías dispuestas en este ámbito del derecho administrativo sancionador".

- Sujeción del procedimiento sancionador al "administrativo común" ex artículo 149.1.18 a de la Constitución.

2. Adecuación de la norma autonómica sancionadora a la normativa básica estatal, sea en la tipificación de infracciones y sanciones (así, en particular, por lo que hace al establecimiento de criterios para la graduación de estas últimas, entre ellos el de la reincidencia7), sea en la previsión de los plazos de prescripción de las infracciones y sancio-

7 Así, por ejemplo, STC 124/2003, fundamento jurídico 8. El carácter básico de la previsión de la reincidencia es explicado así en el fundamento jurídico 16 de la STC 157/2004: 
nes ${ }^{8}$, como canon de constitucionalidad de aquélla. Un canon cuya transgresión comporta la inconstitucionalidad “de carácter mediato o indirecto" de la norma autonómica de comprobarse que "la norma estatal que se reputa infringida por la Ley autonómica es realmente una norma básica”. Para decirlo con las palabras, de las que las frases entrecomilladas están entresacadas, del fundamento jurídico 3 de la STC 166/20029:

“[...] en los términos expresados, entre otras, en la STC 163/1995, de 8 de noviembre $(\mathrm{F} .5)^{10}$, la inconstitucionalidad que se propugna revestiría un carácter mediato o indirecto, en cuanto que la infracción por la Ley autonómica del orden constitucional de distribución de competencias derivará, en su caso, de su efectiva contradicción con la norma estatal básica. Y ello exigirá, como declaró la STC 151/1992, de 19 de octubre (F.1 1), comprobar que la norma estatal que se reputa infringida por la Ley autonómica es realmente una norma básica y, por tanto, dictada legítimamente al amparo del correspondiente título competencial que la Constitución haya reservado al Estado, así como que la contradicción entre ambas normas, estatal y autonómica, es, como se ha dicho, efectiva".

\section{LA COMPETENCIA SANCIONADORA EN MATERIA AMBIENTAL: LA FUNCIÓN DE “UNIFORMIDAD RELATIVA” DE LAS NORMAS SANCIONADORAS ESTATALES}

1. La normativa básica estatal como canon de constitucionalidad de las normas sancionadoras autonómicas impone, cuando de la materia ambiental se trata, pun-

“[...] partiendo del principio funcional propio de la normativa básica, podemos fácilmente advertir que el legislador básico ha querido, simplemente, garantizar que en todo el territorio nacional resulten sancionados con mayor intensidad quienes hayan reincidido en la comisión de alguna infracción que aquellos que no lo han hecho, sin imponer a las Comunidades Autónomas ninguna modalidad técnica en cuanto a la concreción de la sanción que de ello debe seguirse, salvo el aludido tope regulado en el artículo 69.2 de la Ley 7/1996. Ello quiere decir que las Comunidades Autónomas pueden optar, en el libre ejercicio de sus competencias, entre diversas técnicas para dar cumplimiento al mandato básico. Es claro que una de esas técnicas puede ser la aplicación al reincidente de multas más elevadas dentro de los parámetros correspondientes a cada tipo de infracción, según su mayor o menor gravedad. Pero nada impide, y desde luego no lo hace el artículo 69.1 de la Ley 7/1996, que la Comunidad Foral de Navarra decida que en su territorio la ponderación de la reincidencia en la comisión de infracciones se realice a través de la propia tipificación de éstas, configurando un tipo específico del modo en que se realiza por los artículos 69.3 I) y 69.4 e) de la Ley Foral 17/2001".

8 Así, entre otras muchas, STC 166/2002, fundamento jurídico 9.

9 STC 166/2002, de 18 de septiembre; ponente: García Manzano. Recurso de inconstitucionalidad interpuesto contra el primer párrafo del artículo 27, en relación con el Anexo III, y los artículos 103.1 y 113 c), en relación con los números 1, 2 y 4 del artículo 112, de la Ley de la Asamblea Regional de la Región de Murcia 7/1995, de 21 de abril, de la Fauna Silvestre, Caza y Pesca Fluvial.

10 Ponente: Cruz Villalón. Cuestión de inconstitucionalidad promovida por la Sección Primera de la Sala de lo Contencioso-Administrativo del Tribunal Superior de Justicia de Andalucía, en Granada, en relación con diversos preceptos de la Ley de la Comunidad Autónoma de Andalucía 2/1989, de 18 de julio, de Espacios Naturales Protegidos.

11 Ponente: López Guerra. Recurso de inconstitucionalidad interpuesto por el Presidente del Gobierno de la Nación contra diversos preceptos de la Ley del Parlamento de Canarias 2/1987, de 30 de marzo, de la Función Pública Canaria. 
tualizar el sentido del respeto o adecuación a aquélla. Al respecto dice, con remisión a lo establecido en las SSTC 196/1996 y 16/1997, el fundamento jurídico 9 de la antecitada STC 166/2002:

\author{
“[...], como recuerda la STC 16/1997, de 30 de enero (F. 2), en la STC 102/1995 declara- \\ mos el carácter básico de las normas sancionadoras contenidas en los artículos 38 y \\ 39 LCEN [Ley 4/1989, de 27 de marzo, de Conservación de los Espacios Naturales y de \\ la Flora y Fauna Silvestres $]^{12}$. Ahora bien, como señala la STC 196/1996, de 28 de no-
}

12 STC 102/1995, de 26 de junio; ponente: de Mendizábal Allende. Recursos de inconstitucionalidad interpuestos por varias Comunidades Autónomas contra diversos preceptos de la Ley Orgánica 4/1989, de 27 de marzo, sobre Conservación de los Espacios Naturales y de la Flora y Fauna Silvestres, y conflictos positivos de competencia deducidos por distintas Comunidades Autónomas en relación con los Reales Decretos 1.095/1989, de 8 de septiembre, por el que se declaran las especies objeto de caza y pesca y se establecen normas para su protección; 1.118/1989, de 15 de septiembre, por el que se declaran las especies objeto de caza y pesca comercializables; y 439/1990, de 30 de marzo, por el que se regula el Catálogo Nacional de Especies Amenazadas.

El fundamento jurídico 32 de la STC 102/1995, a propósito del carácter básico de las normas sancionadoras contenidas en los artículos 38 y 39 de la Ley 4/1989, dirá:

"La potestad sancionadora de las Administraciones públicas aparece conferida con carácter genérico para cualquier sector, pero también individualizada cuando del medio ambiente se trata (artículos 25.1 y 45.3 C.E.). La Ley $4 / 1989$ cumple así el doble encargo constitucional y tipifica una serie de infracciones administrativas, todas y cada una de las cuales guardan una relación inmediata, directa y unívoca con el medio ambiente, cuyo fundamento es en unas el resultado dañoso y en otras el peligro de que ocurra, dentro de las cuales han de incluirse las aparentemente formales como la realización de ciertas actividades sin licencia o el incumplimiento de las condiciones concesionales o de requisitos legales (artículo 38). No cabe negar a tal repertorio de comportamientos su carácter básico y, por otra parte, mínimo, ya que no excluye o impide la tipificación de otras conductas por las Comunidades Autónomas mediante normas adicionales y su actividad legiferante en desarrollo de la estatal, posibilidad que deja a salvo desde su principio el precepto en cuestión mediante la manida cláusula "sin perjuicio".

La misma respuesta conviene a los reproches que se dirigen a las sanciones cuya clasificación genérica, con la simétrica escala cuantitativa para las multas están necesitadas por sí mismas de un desarrollo legislativo a cargo de las Comunidades Autónomas. El principio de proporcionalidad que anima tal delimitación refleja, a su vez, la importancia que se reconoce a los distintos bienes o intereses jurídicamente protegidos y a la lesión de la cual puedan ser víctimas. Es en suma, una regla mínima, cuya modulación a través de las circunstancias modificativas de la responsabilidad queda en manos de los legisladores y administradores autonómicos para configurarlas en normas y aplicarlas al caso concreto, respectivamente. Por ello, hemos llegado en ocasiones anteriores a la doble conclusión de que tales límites máximos y mínimos de las sanciones no sólo pueden tener carácter básico (STC 227/1988) sino además que, por lo mismo, "no vacían de contenido la competencia legiferante al respecto” de las Comunidades Autónomas (STC 385/1993).

Por su parte, la calificación como muy graves de tres de las infracciones tipificadas en la propia Ley no rebasa el ámbito de lo básico, como también la determinación de ciertas sanciones accesorias, privativas de derechos, así como la posibilidad de utilizar multas coercitivas durante el tiempo necesario para obtener el cumplimiento de lo ordenado, con la fijación de un límite máximo (artículo 39, 1, 2 y 4). El señalamiento de los plazos de prescripción de las infracciones, acomodados a su gravedad, conviene a la seguridad jurídica y, sobre todo, la uniformidad en esta materia procura la igualdad de todos los españoles en el ejercicio de los derechos y en el cumplimiento de los deberes constitucionales cuya garantía, en su dimensión normativa, sólo puede conseguirse mediante la regulación de sus condiciones básicas (artículo 149.1.1 ${ }^{\text {a }}$.E.). La Ley, por omisión deliberada o inadvertida, deja en manos de las Comunidades Autónomas la determinación del tiempo necesario para que prescriban las sanciones, pecuniarias o restrictivas de derechos, una vez impuestas.

Una respuesta específica merece el párrafo tercero del mismo precepto, el artículo 39. Corresponde 226 a la potestad legislativa tipificar las infracciones y determinar las sanciones, cuya imposición es propia de 
viembre (F. 2) $)^{13}$, en el ámbito del artículo 149.1.23 ${ }^{\text {a }}$ CE la legislación básica posee la característica técnica de normas mínimas de protección que permiten normas adi-

la potestad sancionadora de las Administraciones Públicas, inherente a la función ejecutiva. En tal sentido es acompañante y complemento de la "administración" en su acepción objetiva. No cabe desgajar ésta de aquélla. Pues bien, resulta claro entonces que si en esta materia de la protección del medio ambiente se distribuyen las tareas encomendando al Estado la regulación básica para que su desarrollo y ejecución se haga por las Comunidades Autónomas, corresponde a éstas la potestad de imponer las sanciones. En tal sentido es correcta la atribución implícita de tal potestad que contiene la frase inicial del párrafo tercero. También lo es, por razones análogas, el inciso final donde se reserva a la Administración Central la competencia "para la imposición de sanciones en aquellos supuestos en que la infracción administrativa haya recaído en ámbito y sobre materias de su competencia”. Por ello, en la medida en que el Estado tenga competencia para gestionar los Parques Nacionales, según quedó dicho más arriba, esa norma no merecerá reproche constitucional alguno.

Como tampoco lo merece el párrafo quinto. “El Gobierno -dice- podrá, mediante Real Decreto, proceder a la actualización de las sanciones previstas en el apartado 1 de este artículo (39), teniendo en cuenta la variación de los índices de precios al consumo". La norma transcrita es razonable para agilizar la adecuación de las multas a la depreciación monetaria y contiene un criterio objetivo como factor para la determinación de la nueva cuantía, que en consecuencia no se deja al arbitrio ni a la discrecionalidad administrativa salvo en uno de sus aspectos, la oportunidad y conveniencia que nunca puede llevar a anticipar la actualización, aun cuando sí a demorarla. Por ello, no hay agravio alguno al principio de legalidad en el ámbito punitivo que configura nuestra Constitución en el artículo 25.1, ya que el supuesto de incumplimiento funciona en favor o beneficio del presunto responsable por exigirlo así la propia condición de la materia. Por otra parte la disposición general en la cual se llevará a efecto sería fiscalizable directa o indirectamente, a través de los actos de aplicación, por la jurisdicción contencioso-administrativa, cuyas decisiones a su vez, si pusieren en riesgo o menoscabaren un derecho fundamental especialmente protegido, serán residenciables ante este Tribunal Constitucional en la vía de amparo".

13 Ponente: Jiménez de Parga y Cabrera. Recurso de inconstitucionalidad interpuesto por el Presidente del Gobierno de la Nación contra los apartados 1.1.1 y 1.1.17 del artículo primero de la Ley del Parlamento Vasco 1/1989, de 13 de abril, por la que se modifica la calificación de determinadas infracciones administrativas en materia de caza y pesca fluvial.

El fundamento jurídico 2 de esta STC 196/1996 dice así:

“[...] nuestro examen debe necesariamente de partir de lo ya declarado por este Tribunal en la STC 102/1995, pronunciamiento en el que se abordó, en su ínsita dimensión constitucional, el núcleo de la cuestión ahora debatida.

En aquella ocasión analizamos la constitucionalidad de determinados preceptos de la Ley 4/1989, de Conservación de los Espacios Naturales y de la Flora y Fauna Silvestres (L.C.E.N.), declarando, en lo que aquí importa, el carácter básico y, por tanto, la constitucionalidad de las normas sancionadoras contenidas en ese cuerpo legal y relativas a la protección de las especies amenazadas o en peligro de extinción. Así consta expresamente en los fundamentos jurídicos 25, 26 y 32 de la citada Sentencia de este Tribunal Constitucional que ahora damos por reproducidos. Item más: en la STC 156/1995 (fundamento jurídico $8^{\circ}$ ) se declaró -con apoyo en la doctrina de la STC 102/1995- que, con la finalidad de garantizar unos mínimos comunes de protección del medio ambiente en todo el territorio nacional, el Estado puede establecer con carácter básico un catálogo de infracciones -ampliable por el legislador autonómico- que en todo caso se deberán considerar sanciones administrativas.

La posible dificultad en entender las facultades reservadas al Estado por el artículo 149.1.23 C.E. quedó despejada por la STC 170/1989, en cuyo fundamento jurídico $2^{\circ}$ se afirma: “Aquí [en el ámbito del 149.1.23 C.E.] la legislación básica posee la característica técnica de normas mínimas de protección que permiten 'normas adicionales' o un plus de protección. Es decir, la legislación básica del Estado no cumple en este caso una función de uniformidad relativa, sino más bien de ordenación mediante mínimos que han de respetarse en todo caso, pero que pueden permitir que cada una de las Comunidades Autónomas, con competencia en la materia, establezca niveles de protección más altos que no entrarían por sólo eso en contradicción con la normativa básica del Estado. El sentido del texto constitucional es el de que las bases estatales son de carácter mínimo y, por tanto, los niveles de protección que establecen pueden ser ampliados o mejorados por la normativa autonómica, y es a esa posibilidad a la que hace referencia el precepto estatutario". 
cionales o un plus de protección, de forma que la legislación básica del Estado no cumple en este caso una función de uniformidad relativa, sino más bien de ordenación mediante mínimos que han de respetarse en todo caso, pero que pueden permitir que cada una de las Comunidades Autónomas, con competencias en la materia, establezca niveles de protección más altos, que no entrarían por sólo eso en contradicción con la normativa básica del Estado protección del medio ambiente, siendo el sentido del texto constitucional el de que las bases estatales son de carácter mínimo y, por tanto, los niveles de protección que establecen pueden ser ampliados o mejorados por la normativa autonómica. En definitiva, la protección concedida por la Ley estatal puede ser ampliada y mejorada por la Ley autonómica; lo que resulta constitucionalmente improcedente es que resulte restringida o disminuida".

Doctrina cuya aplicación al caso conduce a la declaración de inconstitucionalidad del precepto autonómico que preveía un plazo de prescripción para determinadas infracciones calificadas como muy graves inferior al contemplado en el equivalente de la ley estatal.

2. De modo idéntico se establece para con la cuantía de las sanciones administrativas. El fundamento 10 de la misma STC 166/2002 dirá:

“Como dijimos en la Sentencia del Tribunal C. 156/1995, de 26 de octubre (F. 8), y reiteramos en las sentencias del TC 196/1996, de 28 de noviembre (F.3 $)^{14}$ y 16/1997,

La protección concedida por la Ley estatal puede ser ampliada y mejorada por la Ley autonómica; lo que resulta constitucionalmente improcedente es que resulte restringida o disminuida.

En consecuencia, y por las razones expuestas en las Sentencias mencionadas, la competencia exclusiva del País Vasco sobre la caza no le permite instaurar un régimen administrativo sancionador, en materia de caza o comercialización de especies amenazadas o en peligro de extinción, que disminuya la protección de la legislación básica estatal sobre protección del medio ambiente".

14 El fundamento jurídico 3 de la STC 196/1996 contiene este texto:

"Apreciada la competencia del Estado para dictar legislación básica destinada a la protección del medio ambiente y, en especial, para sancionar administrativamente la caza y comercialización de especies amenazadas o en peligro de extinción -sin perjuicio de las competencias de la Comunidad Autónoma del País Vasco para aprobar normas adicionales de protección-, la cuestión se contrae a determinar si los preceptos impugnados contravienen lo dispuesto en la legislación básica estatal y, en su caso, el orden constitucional de distribución de competencias.

Conviene recordar que en la STC $156 / 1995$ (fundamento jurídico $8^{\circ}$ ) este Tribunal, en la línea de la STC 170/1989, insistió en que el régimen sancionatorio contenido en la L.C.N.E., si bien no cumple "una función de uniformidad relativa", sí establece una protección mínima que debe ser común a todo el territorio nacional; por ello, si el legislador autonómico "hubiera suprimido las infracciones muy graves, o hubiera rebajado sensiblemente la cuantía de la sanción correspondiente, se habría dejado sin efecto la norma estatal".

Desde esta perspectiva, aunque con igual incidencia sobre el asunto que ahora nos ocupa, debe tomarse en consideración -conforme a una reiterada doctrina de este Tribunal- que "las Comunidades Autónomas pueden adoptar normas administrativas sancionadoras cuando, teniendo competencia sobre la materia sustantiva de que se trate, tales disposiciones se acomoden a las garantías dispuestas en este ámbito del derecho sancionador (artículo 25.1 C.E., básicamente), y no introduzcan divergencias irrazonables y desproporcionadas al fin perseguido respecto del régimen jurídico aplicable en otras partes del territorio (artículo $149.1 .1^{\text {a }}$ C.E.)" (STC 87/1985, fundamento jurídico $8^{\circ}$, entre otras muchas).

La diferente cuantía de la multa establecida en la legislación autonómica vasca (de 50.001 a 500.000

228 pesetas) en relación con la prevista en la legislación básica del Estado (de 10.000.001 a 50.000.000 pese- 
de 30 de enero (F. 2$)^{15}$, teniendo en cuenta que el artículo 149.1.23 de la Comunidad Europea permite al Estado establecer en materia de medio ambiente, con carácter básico, una protección mínima que debe ser común a todo el territorio nacional, si el legislador autonómico suprimiere las infracciones muy graves declaradas como tales por la norma estatal básica o redujere sensiblemente la cuantía de la sanción que ésta estableciere para cada una de ellas, habría vulnerado tal normativa básica (en este caso, la LECN), con la consiguiente infracción del orden constitucional de distribución de competencias que resulta del citado artículo 149.1.23 $3^{\text {a }}$ de la Comunidad Europea".

3. En suma, pues, y por lo que atañe a las normas sancionadoras en este ámbito del medio ambiente:

— Las normas básicas estatales son “normas mínimas de protección”.

- Como tales permiten el dictado por las Comunidades Autónomas de "normas adicionales o un plus de protección".

tas), junto a la aminoración de las accesorias, evidencia, de modo palmario, una modificación del esquema sancionatorio que, con el carácter de básico, debe presidir la protección del medio ambiente y la represión administrativa de determinadas conductas gravemente atentatorias al mismo, como lo son la caza y comercialización de las especies amenazadas o en peligro de extinción. Los preceptos impugnados son contrarios a la legislación básica del Estado dictada en el ejercicio de su competencia sobre medio ambiente (artículo 149.1.23 ${ }^{\mathrm{a}}$ C.E.), así como a las exigencias de igualdad esencial en el tratamiento administrativosancionador de la materia, que se derivan del artículo 149.1.1 ${ }^{\mathrm{a}}$ C.E. Razones ambas que conducen derechamente a la declaración de su inconstitucionalidad, por incurrir en una vulneración del referido orden constitucional de distribución de competencias".

15 Ponente: García-Mon y González-Regueral. Recurso de inconstitucionalidad interpuesto por el Presidente del Gobierno de la Nación contra el artículo $46.2^{\text {a }}$ de la Ley del Principado de Asturias 2/1989, de 6 de junio, de Caza.

El fundamento jurídico 2 de esta STC 16/1997, con remisión a lo establecido en las SSTC 102/1995, 156/1995 y 196/1996, dice así:

"[...] se aprecia sin dificultad que la controversia competencial en la que se basa este recurso ya ha sido resuelta, en su estricta dimensión constitucional, por la STC 102/1995, cuya doctrina, aplicada ya en las SSTC 156/1995 y 196/1996, ha de mantenerse también en este caso en el que se plantea el mismo problema.

En la STC 102/1995 enjuiciamos la constitucionalidad de determinados preceptos de la Ley del Estado 4/1989, de Conservación de los Espacios Naturales y la Flora y Fauna Silvestres, declarando, en lo que aquí importa, el carácter básico y, por ende, la constitucionalidad de las normas de naturaleza administrativosancionadora contenidas en sus artículos 38 y 39 . Así figura expresamente razonado en los fundamentos jurídicos 25,26 y 32 de aquella Sentencia, cuyo contenido damos ahora por reproducido.

Con apoyo en esta doctrina, en las SSTC 156/1995 y 196/1996 declaró este Tribunal que el Estado, con la finalidad de garantizar unos mínimos comunes de protección del medio ambiente en todo el territorio nacional, puede establecer con carácter básico un catálogo de infracciones -ampliable por el legislador autonómico- sancionables administrativamente que establecen una protección mínima que debe ser común en todo el territorio nacional. Por ello mismo, si el legislador autonómico "hubiera suprimido las infracciones muy graves o hubiera rebajado sensiblemente la cuantía de la sanción correspondiente, se habría dejado sin efecto la norma estatal" (fundamento jurídico $8^{\circ}$, STC 156/1995). En definitiva, como dice la STC 196/1996, 'la protección concedida por la Ley estatal puede ser ampliada y mejorada por la Ley autonómica; lo que resulta constitucionalmente improcedente es que resulte restringida o disminuida"”. 
- La función que cumplen no es la de "una función de uniformidad relativa" sino la de “ordenación mediante mínimos que han de respetarse en todo caso".

- Esta función de ordenación mediante mínimos permite que las Comunidades Autónomas establezcan "niveles de protección más altos", que por esta sola razón "no entrarían en contradicción con la normativa básica del Estado sobre protección del medio ambiente".

- Al tener las bases estatales un “carácter mínimo", los niveles que protección que aquéllas establecen pueden ser "ampliados o mejorados por la normativa autonómica".

- Ampliación o mejora que, en consecuencia, veda que la protección otorgada por la ley estatal resulte "restringida o disminuida" por la ley autonómica.

\section{POTESTAD SANCIONADORA Y SEGURIDAD SOCIAL}

1. La competencia legislativa para tipificar infracciones y sanciones, en los términos antecitados, arrastra, como integrante de la competencia ejecutiva, la potestad para imponer las oportunas sanciones. En los términos sintéticos del fundamento jurídico 4 de la STC 51/2006 ${ }^{16}$ :

“[...] como ha señalado de forma reiterada este Tribunal, la atribución de la competencia ejecutiva comprende la de la potestad sancionadora en la materia sobre la que se ejerce (SSTC 87/1985, de 16 de julio, fundamentos jurídicos $1^{\circ}$ y $2^{\circ} ; 227 / 1988$, de 29 de noviembre, fundamento jurídico 29; y 195/1996, de 28 de noviembre, fundamento jurídico $\left.8^{\circ}\right)$ ".

2. Este principio general ha de pasarse por el fulcro de las peculiaridades de determinados supuestos, tal y como la atribución competencial es diseñada por la Constitución. Así ocurre en la materia de la Seguridad Social, que atribuye al Estado competencia exclusiva sobre "legislación básica y régimen económico de la Seguridad Social, sin perjuicio de la ejecución de sus servicios por las Comunidades Autónomas" (artículo 149.1.7 ), y cuyo alcance es perfilado así, con remisión a lo sentado en la STC 195/1996, en el reseñado fundamento jurídico 4 de la Sentencia del Tribunal Constitucional 51/2006:

16 STC 51/2006, de 16 de febrero; ponente: Aragón Reyes. Conflicto positivo de competencia promovido por el Consejo Ejecutivo de la Generalidad de Cataluña en relación con el artículo 18.3 del Reglamento general sobre procedimientos para la imposición de sanciones por infracciones de orden social y para los expedientes liquidatorios de cuotas de la Seguridad Social, aprobado por Real Decreto 928/1998, 
“En relación con la potestad sancionadora en materia de Seguridad Social, este Tribunal tuvo ocasión se señalar en su STC 195/1996, de 28 de noviembre, al analizar el recurso de inconstitucionalidad interpuesto por el Gobierno Vasco contra la Ley 8/1988, de 7 de abril, de infracciones y sanciones en el orden social, que el citado precepto constitucional obliga a distinguir, desde un punto de vista competencial, entre la Seguridad Social y su régimen económico. Respecto a la primera es evidente que, ostentando la Comunidad Autónoma competencias ejecutivas, 'le corresponde ejercitar las potestades sancionadoras que garanticen el cumplimiento de la legislación básica estatal y de la autonómica que la desarrolle (STC 102/1995, fundamento jurídico 32). En cuanto a la segunda, la delimitación del ámbito de actuación de la Comunidad Autónoma requiere mayores precisiones, pues la atribución al Estado o a las Comunidades Autónomas del régimen en una determinada materia comprende, desde luego, la totalidad de las competencias normativas sobre la misma (SSTC 84/1982, fundamento jurídico $4^{\circ}$ y 38/1983, fundamento jurídico $3^{\circ}$ ); pero implica también un 'plus': además de la legislación, puede comportar la atribución de las competencias de ejecución necesarias para configurar un sistema materialmente unitario. Eso es lo que sucede en el caso del régimen económico de la Seguridad Social' (STC 195/1996, de 28 de noviembre, fundamento jurídico $\left.6^{\circ}\right)$ ".

Distinción, pues, entre la Seguridad Social, de un lado, y el régimen económico de la Seguridad Social, de otro, y que, a los efectos de la atribución de la potestad sancionadora, se traduce en el pertinente deslinde competencial:

“En virtud de ello, la citada Sentencia efectuó el deslinde competencial afirmando, en primer lugar, la potestad sancionadora autonómica (en aquella ocasión, de la Comunidad Autónoma del País Vasco) y excluyendo, en consecuencia, la del Estado, 'para declarar la concreta existencia de infracciones y sancionar aquellas que no guarden relación con el régimen económico de la Seguridad Social', así como para 'aquellos supuestos en que la potestad punitiva recae sobre actos instrumentales respecto al nacimiento y mantenimiento de la obligación de contribuir (inscripción, afiliación, altas y bajas, etc.)', reservando por el contrario al Estado, como propia de su competencia en materia de régimen económico, la potestad sobre 'aquellas infracciones que recaen directamente sobre la actividad económica de la Seguridad Social, esto es, las que definen ilícitos que se hallan inmediatamente referidos a la percepción de sus ingresos o a la realización de los gastos correspondientes' (STC 195/1996, de 28 de noviembre, fundamento jurídi$\left.\operatorname{co} 8^{\circ}\right)$.

En suma:

“Debemos pues concluir que la competencia para la imposición de las sanciones en materia laboral y de Seguridad Social a las cuales se aplica el artículo 18.3 objeto del presente conflicto de competencia corresponde, en principio, a la Generalidad de Cataluña, excepto en el caso de aquellas que han quedado reservadas al Estado en materia de régimen económico de la Seguridad Social". 
debatido:

Conclusión a la que sigue la debida precisión que enmarca la resolución del caso

"En todo caso, sí interesa resaltar que el presente conflicto no cuestiona a quién deba atribuirse la competencia para la imposición de las sanciones en cada uno de los ámbitos materiales sancionadores a los que se aplica el reglamento de procedimiento en el que el precepto controvertido se inserta, sino exclusivamente la cuestión más precisa de determinar si, en aquellos casos en que la competencia sancionadora corresponda a la Generalidad de Cataluña, el citado precepto vulnera las competencias de la Generalidad para la regulación de su propia competencia funcional y la organización de los servicios necesarios para ello".

3. ¿A qué se contrae, pues, el precepto objeto de la controversia? Precepto que no es otro sino el artículo 18.3 del Real Decreto 928/1998, de 14 de mayo, por el que se aprueba el Reglamento general sobre procedimientos para la imposición de sanciones por infracciones de orden social y para los expedientes liquidatorios de cuotas de la Seguridad Social, cuyo texto es el que sigue:

"Si se formulasen alegaciones en plazo contra el acta de infracción, el órgano al que corresponda resolverlas podrá recabar informe ampliatorio, que se emitirá en quince días, del Inspector o Subinspector que practicó el acta, que asumirá las funciones de instructor del expediente. El citado informe será preceptivo si en las alegaciones se invocan hechos o circunstancias distintos a los consignados en el acta, insuficiencia del relato fáctico de la misma, o indefensión por cualquier causa.

Dicho informe valorará expresamente las pruebas aportadas o que se hubiesen practicado, y las alegaciones producidas, y contendrá propuesta definitiva de resolución. Si el expediente derivara de acta visada por Inspector, el informe del Subinspector que la practicó será objeto de conformidad por el Inspector que visó el acta originadora de actuaciones, en los términos que establece el artículo 12.2 y 3 de este Reglamento".

Y, en concreto, "el presente conflicto de competencia se refiere al contenido del apartado 3 del artículo 18, es decir, a la intervención, facultativa o preceptiva, del Inspector de Trabajo que practicó el acta de infracción cuando contra la misma se hayan formulado alegaciones por el presuntamente responsable". Más precisamente aún, dicho conflicto se ciñe "a un aspecto concreto del citado apartado 3, cual es el relativo a la asunción por el Inspector de Trabajo del que se ha recabado informe ampliatorio -sea éste facultativo o preceptivo- de las funciones de instructor del expediente sancionador, incluida la función de elaboración de la propuesta definitiva de 232 jurídico 5). 
Delimitación del objeto del conflicto que conduce, finalmente, a una estimación parcial del conflicto positivo de competencia planteado por el Consejo de Gobierno de la Generalidad de Cataluña ${ }^{17}$. fallo:

17 1Los cuatro últimos párrafos del fundamento jurídico 7 desarrollan el alcance del expresado

"Por ello debemos concluir que el apartado 3 del artículo 18 del Reglamento general sobre procedimientos para la imposición de sanciones por infracciones de orden social y para los expedientes liquidatorios de cuotas de la Seguridad Social, aprobado por Real Decreto 928/1998, de 14 de mayo, vulnera las competencias de la Generalidad de Cataluña al establecer en su párrafo primero que el Inspector o Subinspector que practicó el acta de infracción, cuando se hubiera recabado del mismo informe ampliatorio sobre las alegaciones formuladas por el sujeto o sujetos imputados, asumirá las funciones de instructor del expediente sancionador, toda vez que en aquellos casos en que la competencia sancionadora corresponda, por razón de la materia, a la Generalidad de Cataluña, corresponderá igualmente a ésta la determinación del órgano encargado de la instrucción del expediente sancionador.

$\mathrm{E}$, igualmente, el precepto considerado vulnera las competencias de la Generalidad de Cataluña en los mismos casos a los que se acaba de hacer referencia, al establecer, en su párrafo segundo, que el Inspector o Subinspector deberá incluir, en el informe que al efecto elabore, la "propuesta definitiva de resolución", pues dicha propuesta definitiva, a la que se refiere la disposición adicional cuarta de la Ley 42/1997, de 14 de noviembre, de ordenación de la Inspección de Trabajo y Seguridad Social, sin incluir la expresión "de resolución”, sólo puede ser entendida como la que con tal carácter definitivo, ratificando o corrigiendo la propuesta inicial contenida en el acta a la vista de las alegaciones y pruebas practicadas, formula el funcionario actuante al órgano instructor del expediente sancionador, y no como propuesta definitiva “de resolución", que es la que deberá efectuar el órgano instructor del expediente y elevar al órgano competente para resolver.

Sin embargo, interesa resaltar que ningún problema competencial plantean ambas menciones en aquellos supuestos en que, por razón de la materia, la competencia sancionadora corresponda a la Administración del Estado, pues, como ya hemos apreciado, el precepto impugnado tiene capacidad de proyección sobre otros ámbitos materiales en los que no se ha denunciado infracción competencial alguna.

En resumen, el mencionado artículo 18.3 vulnera las competencias de la Generalidad de Cataluña al atribuir al Inspector o Subinspector de Trabajo la función de instructor y al disponer que la propuesta definitiva que esa Inspección formule lo sea “de resolución”, en los casos en que la competencia sancionadora corresponda, por razón d ela materia, a la Generalidad. Sin embargo, ningún problema competencial plantean ambas determinaciones en aquellos supuestos en que, por razón de la materia, la competencia sancionadora corresponda a la Administración del Estado. Procede, por ello, estimar parcialmente el presente conflicto positivo de competencia en los términos señalados, declarando la titularidad de la competencia controvertida y sin declaración de nulidad del precepto correspondiente". 
